\title{
ACCIÓN COLECTIVA EN RED Y PERCEPCIÓN POLITICA DE CIBERNAUTAS EN MÉXICO
}

\author{
Dr. Sergio Octavio Contreras Padilla \\ Universidad Autónoma de Durango, Zacatecas, México \\ scontrerasp@gmail.com \\ ORCID iD: https://orcid.org/0000-0002-5060-5820
}

Recibido el 30 de diciembre de 2018

Aceptado el 12 de julio de 2019

\section{Resumen}

El presente artículo analiza las nuevas formas de acción colectiva en red y la percepción política que tienen los usuarios de internet en México. Para lograr tal objetivo se realizó un estudio de caso del colectivo \#YoSoy132, considerado el movimiento en red de jóvenes más importante de los últimos años y uno de los principales grupos contestatarios del sistema político mexicano. A través de una metodología mixta se llevó a cabo un análisis de redes sociales para comprender las relaciones de los seguidores del colectivo en Twitter y se aplicó una encuesta en línea para conocer las percepciones políticas de los usuarios. Los resultados muestran los cambios en los modos de participación social en lo político, así como las concepciones colectivas sobre democracia, política y libertad, producto del uso de las nuevas tecnologías de la información y la comunicación (TIC).

Palabras clave: acción colectiva, redes sociales, tecnopolítica, internet, México, Twitter 


\title{
COLLECTIVE ACTION IN NETWORK AND POLITICAL PERCEPTION OF NETIZENS IN MEXICO
}

\begin{abstract}
This article analyzes the new forms of network collective action and the political perceptions that Internet users have in Mexico. To achieve this goal, a case study of the \#YoSoy132 collective was carried out, which is considered the most important network movement of young people in recent years and one of the main protest groups of the Mexican political system. Through a mixed methodology a network analysis was carried out in order to understand the relationships of the followers of the collective on Twitter and an online survey was applied in order to know the political perceptions of the users. The results show the changes in the modes of social participation in politics as well as the collective conceptions of democracy, politics and freedom resulting from the use of new information and communications technology (ICT).
\end{abstract}

Keywords: collective action, social networks, technopolitics, Internet, Mexico, Twitter 
Introducción

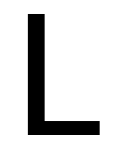

a penetración de las nuevas tecnologías en las sociedades contemporáneas generó cambios profundos a nivel individual y colectivo. En los albores del siglo XXI se desarrollaron medios de comunicación sociales que proporcionaron a las personas nuevas formas de relacionarse y de encontrar información dentro de un vasto sistema tecnológico (Abbate, 2008:151). En décadas recientes se gestaron algunas teorías que pretendían explicar los efectos de esta revolución técnica cuya columna vertebral es internet. Entre los principios más notables sobresalen la "sociedad de la información" (Masuda, 1984 y Bell, 1991) y la "sociedad red" (Castells, 1997 y Van Dijk, 2006). En el campo político, uno de los principales usos de las nuevas tecnologías ha sido la comunicación. En este sentido, la política consiste en la toma de decisiones y la comunicación en el lugar público donde tales decisiones son conocidas (Canel, 2006). En los espacios de información las decisiones políticas siempre encuentran posturas encontradas que se manifiestan como reacciones civiles en contra del sistema establecido (Arditi, 1995). Para algunos estudiosos cuando este tipo de acciones se auxilian de aparatos pueden conceptualizarse como tecnopolítica (Sampedro, 2011; Sampedro, Sánchez y Poletti, 2013; Sierra, 2013 y Monge, 2017), es decir, la capacidad de individuos y colectividades para utilizar las tecnologías con el fin de inventar nuevas formas de acción. Esta especie de actividades en línea también se han conceptualizado dentro de la cultura de internet como ciberactivismo o hacktivismo (Ugarte, 2007; Tascón y Quintana, 2012; Soengas y Assif, 2017 y Karagiannopoulos, 2018).

A diferencia de los medios de comunicación tradicionales -televisión, radio, cine y prensa- que durante el siglo pasado jugaron un rol vertical en el control y distribución de la información, los nuevos medios posibilitan a las personas crear sus propios contenidos sin necesidad de intermediarios. Según el informe Global Internet Report 2014 elaborado por la asociación internacional Internet Society, existe un crecimiento constante por parte de instituciones públicas y gobiernos en el uso de innovaciones para comunicarse con los ciudadanos. En este nuevo escenario las personas opinan sobre lo que otros opinan, los políticos tienen la capacidad de relacionarse directamente con los usuarios y los conflictos sociales pueden pasar de la red a la calle (Rincón y Uribe, 2015). Con internet las acciones colectivas en las contiendas políticas fueron llevadas más allá de los límites territoriales de los Estados. Las nuevas tecnologías facilitaron la comunicación de los movimientos sociales por encima de las fronteras (Tilly, 2008 y Tilly y Woods, 2010). En los últimos años a nivel planetario se presenciaron acciones colectivas mediadas por la tecnología. Así ocurrió entre los años 2010 y 2013 con la llamada primavera árabe (Priego, 2011; Ben Jelloun, 2011 y Gutiérrez, 2017); en 2011 los indignados en España (Roitman, 2012; Castañeda, 2012 y Peña-López, Congosto y Aragón, 2014); entre 2011 y 2012 el movimiento occupy en Estados Unidos (Lubin, 2012; Sitrin, 2012 y Kavada, 2015); en 2012 en México la acción del 
colectivo de jóvenes \#YoSoy132 (Alonso, 2013; Gómez y Treré, 2014; Torres, 2015 y Welp, 2015) y en 2014 las protestas organizadas en red en Hong Kong, Brasil y Venezuela (Yuen, 2015; Cai, 2016 y Flowerdew y Jones, 2016).

La tecnología empleada con fines políticos visibiliza los problemas sociales y mediante las formas electrónicas de comunicación los usuarios exigen soluciones a los sistemas políticos. Las personas conectadas a las redes son capaces de impulsar y catalizar nuevos modos de participación en temas públicos y políticos (Adame, 2015). Esto es posible porque la tecnología de internet, las comunicaciones inalámbricas, los medios de comunicación digitales y una serie de herramientas de software social provocaron el desarrollo de redes de comunicación omnidireccionales. Es decir, existe cierta autonomía de los sujetos comunicantes respecto a las empresas de comunicación predominantes que han operado bajo un modelo vertical (Castells, 2010:101-157). Debido a la horizontalidad las personas abandonan su rol pasivo como receptores de información para construir sus propios mensajes (Zanoni, 2008). El individuo activo no sólo se expone a contenidos políticos, sino que también puede producirlos (Anduiza, Cristancho y Cantijoch, 2012). Desde la tecnopolítica los colectivos con acceso a internet tienen mayores posibilidades de injerencia sobre lo político. Para lograrlo, utilizan las herramientas digitales a su alcance (Bacallao-Pino, 2016): redes sociodigitales como Facebook o Twitter; programas de mensajería como WhatsApp o Messenger; servicio de videos en línea como Vimeo o YouTube; bitácoras personales; páginas web y todo un arsenal de repertorios para la acción colectiva. Estas técnicas generan productos culturales que se caracterizan por ser maneras de contestación a los sistemas de poder cuando se presentan conflictos que dañan la confianza en lo político. Hay casos donde sólo se exige una afirmación de identidad, como cuando un líder pide el apoyo de sus seguidores sin que exista un conflicto de por medio, pero cuando las demandas al realizarse afectan los intereses de otros, entonces los repertorios se convierten en medios de contestación (Tilly, 2002).

En años recientes el uso de tecnologías con fines políticos se integró paulatinamente a la acción colectiva. La indignación social se transparentó en las redes de internet. Las personas se organizaron para apropiarse del espacio urbano como una nueva estructura de empoderamiento (Toret, 2015), tal es el caso de los movimientos feministas que adoptaron a nivel global el uso de novedosas herramientas para recolectar información, compartirla, transformarla y crear redes de colaboración en busca de nuevos derechos humanos (Gago, 2019) - la aparición de entidades políticas alternativas como respuesta a la crisis de la democracia representativa como ocurrió con los llamados "partidos piratas" en Alemania, Suecia, República Checa, Islandia y Ucrania (Tormey, 2015). En el caso de América Latina, las movilizaciones son un híbrido cultural donde el uso tecnopolítico genera esferas de diálogo y significado entre los grupos en competencia y la identidad es construida, negociada o recompuesta (Sierra y Gravante, 2018). Las innovaciones también pueden ser utilizadas como formas 
políticas en contra de lo civil: en China el gobierno emplea la nueva tecnología para controlar los protocolos de conexión y bloquear contenidos (Li, 2016). Es precisamente el control de la información uno de los aspectos más estudiados en el campo tecnopolítico. Mientras el poder político intenta limitar la circulación de datos que afecten sus intereses, la sociedad conectada en red transmite en directo desde los teléfonos móviles las manifestaciones, las represiones y los campamentos de los activistas (Olesen, 2015).

En México, el llamado movimiento \#YoSoy132 se constituyó como la primera acción colectiva de jóvenes originada en las redes de internet con un impacto importante en la esfera política. El colectivo surgió el 11 de mayo de 2012 en la Universidad Iberoamericana durante la visita de Enrique Peña Nieto, entonces candidato presidencial por la coalición "Compromiso por México" entre el Partido Revolucionario Institucional (PRI) y el Partido Verde Ecologista de México (PVEM). Después de presentar su plataforma de gobierno, el aspirante fue cuestionado por un grupo de universitarios y para evitarlos se escondió en un baño. Al siguiente día, Televisa -la cadena de televisión abierta con mayor cobertura en el país-, varias empresas de radio y periódicos interpretaron el encuentro como exitoso. Los medios tradicionales calificaron a los universitarios de "vándalos" y de haber intentado sabotear el acto bajo intereses políticos. Tres días después del incidente, 131 jóvenes grabaron un video que fue publicado en YouTube en el que parecieron diciendo su nombre y mostrando su credencial de estudiantes. La producción se hizo viral, miles de personas de otras universidades y del extranjero se sumaron a la indignación (Domínguez, Greene, Lawson y Moreno, 2015). Con la etiqueta \#YoSoy132 los internautas organizaron desde internet marchas, tomas de calles y edificios para exigir a los medios tradicionales no tergiversar la información. Las protestas continuaron hasta el día que Peña Nieto asumió la presidencia de la República.

En los últimos años \#YoSoy132 utilizó las redes de Facebook y Twitter como espacio contestatario del poder político. Destacan dos periodos: el primero, entre 2012 y 2013, cuando el gobierno federal aprobó reformas en materia energética, en telecomunicaciones, en educación y en trabajo. Y en 2014, ante el caso de los 43 estudiantes normalistas del poblado de Ayotzinapa, desaparecidos por autoridades municipales y miembros del narcotráfico. Investigar las formas de comunicación electrónicas, los seguidores y los mecanismos que sostienen una red es comprender los nuevos modos de participación en lo político. El presente estudio está dividido en dos partes, la primera es un análisis de redes sociales a perfiles en Twitter y la segunda es un cuestionario en línea aplicado a internautas. El objetivo del estudio es identificar los elementos que permiten la comunicación en red desde el uso político de la tecnología y conocer la percepción que tienen los usuarios sobre lo político. El artículo intenta responder las siguientes preguntas de investigación: ¿cuáles son los elementos que sostuvieron un colectivo en línea?, ¿qué papel jugaron los seguidores en el sostenimiento de la red?, ¿cuáles fueron los usuarios que más participaron en la red?, ¿qué caracterizó 
la participación de los usuarios en los temas del colectivo?, ¿cuáles son los consumos informativos de los cibernautas?, ¿qué opinan los usuarios sobre política y democracia? y ¿qué representa para las personas la nueva tecnología? Inicialmente se presenta un panorama teórico sobre política, espacio público, acción colectiva y tecnología. Posteriormente se muestra la metodología utilizada y se ofrece al lector los principales hallazgos obtenidos. Los datos son analizados y al final se presenta una conclusión desde la perspectiva de la tecnología con fines políticos y la acción colectiva en red.

\section{Política y espacio público}

El tema que se aborda en el presente trabajo es un fenómeno que puede enmarcarse dentro de los cambios globales de finales del siglo $X X$, caracterizado por una comunicación individual mediada por artefactos digitales. En este apartado se intentará dar respuesta al hecho de que las tecnologías de la información no sólo son aparatos para la comunicación, también encarnan nuevas y cambiantes formas de participación política. Bobbio (1986) considera que toda participación parte de lo individual y se inserta en la colectividad. Si bien la conducta individualista nace de la esfera privada y está determinada en gran medida por la formación cívica, su acción no se limita a los procesos electorales. Las personas pueden actuar políticamente en otras esferas. Según Turner (1990: 189) en las sociedades modernas las personas son más activas y participativas en los asuntos públicos que en épocas anteriores. Tal participación se ejerce dentro de ciertas reglas condicionadas por el tipo de democracia que regulan la organización social: acudir a votaciones, escribir cartas a representantes, firmar peticiones, asistir a manifestaciones, realizar organizaciones voluntarias, otorgar donaciones, etcétera. Para Sartori (1994) la participación de los ciudadanos en temas políticos es importante para la mejora continua de la democracia. El pensador italiano considera que a mayor participación de lo civil en asuntos políticos será mejor el nivel democrático. En las últimas décadas se propusieron a nivel mundial diversos mecanismos para integrar a la sociedad en la toma de decisiones de lo político con base en la discusión y deliberación de asuntos de interés colectivo (Velasco, 2009). La posibilidad de participación en lo político ocurre en tanto exista libertad de acción. Para Arendt (1996) la libertad engendra la capacidad de cambio social en tanto exista un espacio donde las personas puedan ejercer su libertad para manifestar sus ideas. En consecuencia, la acción política descansa en la exposición externa de la libertad del individuo para llevar a cabo una acción o el inicio de algo nuevo. La opinión individual originada en la información disponible sobre acontecimientos es una de las principales manifestaciones de libertad política de la sociedad actual.

Las teorías sobre la libertad de participación política en espacios públicos y su relación con lo político son concebidas tradicionalmente desde la organización social, las visiones culturales y fenomenológicas, y los procesos políticos. El espacio público es, en todo caso, el centro donde se visibiliza la acción individual 
y colectiva de lo político. Según Rabotnikof (2006) la noción de espacio público tiene tres acepciones. La primera se refiere a aquello que es "común" a todos, donde prevalece el interés de la colectividad sobre el interés individual. La segunda tradición está representada por aquello que es "visible" a todos, lo que es publicitado para dar legitimidad al poder político, con sus excepciones o limitantes. Y la tercera definición comprende aquello que es "abierto" en contra de lo que es "cerrado". En las tres concepciones existe una "tensión" dentro del espacio público entre distintos actores civiles y políticos. Desde la teoría crítica el espacio público es un escenario de racionalización y de emancipación, una mediación entre la sociedad y el Estado. Para Habermas (1986, 1999), la libertad de opinión en las sociedades modernas da legitimidad a las normas del sistema político y permite a los sujetos privados hacer sus demandas a los sujetos públicos mediante normas vinculantes. El filósofo alemán desarrolló un modelo de democracia deliberativa donde la discusión racional sobre los pros y contras de los asuntos públicos llevará a los participantes a un consenso. Sin embargo, uno de los principales problemas que enfrenta hoy en día tal deliberación es que la nueva tecnología da el derecho a todos de participar en igualdad de circunstancias aun cuando cada individuo piense y viva en contextos informativos diferentes (Elster, 2001).

El desarrollo de los medios de comunicación transformó el espacio social donde las personas se informaban sobre lo público. Thompson (1998) asegura que en las sociedades modernas los asuntos públicos se discuten mediante el uso de sistemas tecnológicos que separan a los receptores del contexto original donde se produjo el acontecimiento. En estos espacios públicos lo político se convierte en un fenómeno mediático, entendido este como la exteriorización de procesos mentales bajo la forma de un dispositivo material dado (Verón, 2005, 2015). Es por esto que la sociedad actual atraviesa por un proceso de mediatización más profundo que las sociedades que le precedieron debido a la implantación en la trama social de una gran variedad de tecnologías de la comunicación. Las prácticas se transforman por el hecho de que hay medios. El campo político es uno de los sectores donde la mediatización es más visible. Los gobiernos emplean los sistemas comunicativos para visibilizar los temas que quieren que la sociedad conozca. En el espacio mediatizado se transparenta la agenda política, los intereses mediáticos y sociales. Es por esto que los temas que por lo general abordan las personas en los lugares físicos no difieren en gran medida de aquellos que se discuten en los medios (Bonilla, 2002). En esta nueva circunstancia el individuo clama a través de los medios ser escuchado, y en este proceso lo público y lo privado son sometidos a un proceso de resignificación: lo público se percibe como un lugar donde se visibiliza y se reconocen las demandas sociales (Colina, 2005).

Una vasta cantidad de investigaciones sobre la mediatización del campo político se han desarrollado en años recientes: la función ideológica de los mensajes, el control informativo del gobierno, la influencia en los procesos electorales, la 
participación civil en campañas, etcétera. Desde las teorías de la comunicación política la mediatización transformó las formas de producción y difusión de contenidos simbólicos que desarrollan principalmente las instituciones políticas para el ejercicio del poder. El político, los medios de comunicación y el público conforman un sistema donde se ejercen las libertades informativas como forma de participación política (López, Gamir y Valera, 2018). Según Melucci (1996) las demandas y los conflictos políticos actuales se escenifican en el campo simbólico de la comunicación. En estos sitios las personas incorporan a su vida una gran cantidad de información producida por los medios de difusión y por las nuevas tecnologías, pero no sólo emiten postura al respecto, sino que también pueden participar culturalmente en la creación de contenidos. La información política que difundía el sistema político a través de los medios de comunicación tradicionales ahora converge en nuevas estructuras generadas por internet. Actualmente prevalece una especie de híbrido que fusiona innovaciones y algunas características de los viejos medios (Logan, 2010). En este emergente espacio público acontecen las nuevas formas de interacción entre lo social y lo político. Algunas investigaciones demostraron que los ciudadanos que utilizan las nuevas tecnologías están mejor informados de lo político que quienes sólo se informan a través de medios tradicionales (Haythornthwaite, 2012). La tecnopolítica ofrece a los individuos, actores políticos y grupos de la sociedad civil organizada plataformas para difundir todo tipo de opiniones y decisiones políticas. Las redes de internet son lugares de prefiguración donde la gente habla por su propia voz (Rovira, 2017).

\section{Acción colectiva y tecnología}

Desde la economía y la ciencia política se ha teorizado sobre la organización de los individuos para lograr satisfacer sus demandas. En las sociedades modernas existe una lógica que orienta a las personas a unirse a grupos para alcanzar un determinado fin. Las organizaciones formales -sindicatos, asociaciones civiles, defensores de derechos, etcétera- y las no formales -espontáneas y sin estructura formal- ponen en marcha acciones para lograr sus objetivos. Para Olson (1992) la participación de los grupos sociales en asuntos de interés público dependerá en gran medida de incentivos. Se trata de una elección racional y egoísta: la persona escoge lo que es más adecuado para sus fines individuales. En esta perspectiva, la acción colectiva puede entenderse como un conjunto de actividades unidas por intereses comunes de los participantes y que para conseguirlas se desarrollan movilizaciones específicas (Funes y Monferrer, 2003). Según Tarrow (1999) las acciones se manifiestan a través de diversos repertorios como peticiones, asambleas, huelgas, marchas, ocupaciones, etcétera, que se inscriben en la cultura a la cual pertenecen los participantes y se comunican al resto de la sociedad. Un ciclo de acción colectiva ocurre cuando las acciones de las personas se extienden por una sociedad entera y se convierte en movimiento social cuando las acciones se basan en redes compactas y estructuras de conexión que permiten mantener una oposición de conflicto con adversarios poderosos (Tarrow, 
2004:33). La crisis que genera la acción en contra de un actor social deriva en una contienda política, es decir, en un enfrentamiento público entre actores (McAdam, Tarrow y Tilly, 2001).

Algunos autores consideran que la acción colectiva no depende sólo de intereses individuales y grupales sino de lógicas múltiples. Por ejemplo, en América Latina aspectos locales como la identidad y el territorio son factores que inciden en la acción colectiva. En Europa la mediatización es importante para la difusión de las demandas de los colectivos (Fillieule y Tartakowsky, 2015). La comunicación de la acción colectiva también muestra diferencias según los contextos donde se enmarquen los problemas (Cardoso, 2010). El registro mediatizado de los problemas políticos en Venezuela desde el año 2017 es muy diferente a la guerra civil en Siria que se mantiene vigente desde el 2011. En el activismo en internet confluyen variadas formas de acción colectiva que explican los conflictos sociales propios de la sociedad contemporánea. En las redes, la acción colectiva aparece como una forma alternativa de abordar los problemas sociales del sistema global (Valencia y García, 2014). Las herramientas digitales posibilitan la producción y articulación de redes para visibilizar los problemas en escenarios globales y crear movimientos de opinión favorables (Celorio, 2011:87). Sin embargo, el uso de las redes digitales como formas de comunicación no garantiza una participación política plena: los internautas optan por hacer "clic" en los enlaces o compartir contenido creyendo ingenuamente que su expresión política tendrá un impacto sustancial en el mundo político real (Kwak et al., 2018:199).

Algunas posturas teóricas consideran que un factor que incide en la acción colectiva contemporánea es la conectividad tecnológica. De acuerdo a Internet World Stats, a principios del año 2019 el 56.8\% de la población del planeta tenía acceso a internet. La conexión mediante la red enriquece la inteligencia colectiva al explorar las personas puntos de vista diferentes (Kerckhove, 2009). Esta interacción propicia un intercambio intercultural y político entre los usuarios (García, 2004, 2007). En el campo electoral, internet es utilizado por los contendientes como foro para sus actividades políticas. La red es una extensión de la política y de la comunicación política (Katz y Rice, 2005). Los participantes se informan en la red, se organizan para la acción y hacen públicas sus posturas (Anduiza, Cantijoch, Gallego y Salcedo, 2010). Desde que internet fue abierto para su uso social en 1993, existen numerosos estudios que relacionan el papel de las redes digitales con la acción social. Desde la tesis constructivista la tecnología en toda su extensión y profundidad -incluidos, especialmente, sus aspectos más técnicos- es el resultado de complejos procesos de su relación con la sociedad, la política y la economía (Hughes, 1983; Callon y Law, 1989). La tecnología no propicia de manera autónoma la acción colectiva. Factores culturales de un orden muy variado pueden llegar a desempeñar un papel importante en el uso de los artefactos (MacKenzie y Wajcman, 1985). Algunas de las primeras investigaciones descubrieron que las redes pueden aumentar la participación de las personas sobre el desempeño de las instituciones públicas 
(Grossman, 1995; Hill y Hughes, 1998); que las redes son capaces de democratizar ciertas esferas políticas (Sobchack, 1995) y pueden servir a grupos relativamente pequeños para llamar la atención de un público más numeroso (Rash, 1997). Cohen y Rai (2000) realizaron uno de los trabajos pioneros sobre el uso tecnológico con fines políticos y descubrieron seis tipos de movimientos en línea: ecologistas, pacifistas, religiosos, sindicales, feministas y defensores de derechos civiles. Según Castells (2012:552) la red refleja un enfrentamiento entre formas verticales y formas horizontales de comunicación. Bajo esta tesitura, la acción colectiva en red puede definirse como un conjunto de actividades cohesionadas por los fines que comparte un grupo de individuos y cuyos intereses pueden emerger de las ideas o ser extensiones de los problemas que ocurren en la calle (Jiménez y Ramírez, 2010; Spier, 2017).

El uso de tecnología de la comunicación con fines políticos se conceptualizó a finales de la década de los 90 del siglo XX como una forma de integrar a los ciudadanos a tareas del poder político: transparencia, rendición de cuentas, participación en la toma de decisiones, etcétera, (Kurban, Peña-López y Haberer, 2017). Perspectivas como gobierno abierto, conocimiento abierto, sociedad abierta o e-government correspondían a una nueva forma de participación donde el sistema político tomaba en cuenta a la sociedad. Con la expansión de las innovaciones la tecnopolítica quedó rebasada como concepto. Ya no representa sólo una forma comunicativa para alcanzar fines colectivos. La apropiación técnica supone procesos que dan identidad a los grupos en sus dimensiones expresiva y cognitiva (Sierra, Maniglio y Fávaro, 2018). La interconectividad deslocalizada en red representa una posibilidad para romper el cinturón de protección que los poderes tienen sobre la distribución de información. En esta nueva plaza-red las insurrecciones en clave tecnopolítica alteran los anclajes de sentido, propician el distanciamiento frente a lo asumido como normal o anormal e invitan a pensar y sentir más allá de lo dado como cierto, natural, y con ello se abren nuevas posibilidades de hacer política (Reguillo, 2017). Hoy en día las subjetividades políticas y la acción colectiva surgen de la articulación y fertilización recíproca entre la vida cotidiana y la vida política, entre el mundo de internet y el de las plazas públicas, entre las redes sociales y la convivencia en los espacios militantes (Pleyers, 2018:89).

\section{Metodología}

En el presente apartado se muestra la metodología utilizada. El campo de investigación fue internet y los cibernautas que participaron dentro de la red de Twitter del colectivo \#YoSoy132. La investigación se orientó por el enfoque propuesto por Hine (2004) para abordar el objeto de estudio como cultura características de la comunicación en red-y como artefacto cultural -sentido que otorgan los usuarios a la tecnología-. En este contexto se analizaron las relaciones de participación de los seguidores y las percepciones de los usuarios desde la propia tecnología. Esta sección se divide en dos partes, la primera corresponde a 
la metodología para el análisis de redes sociales (ARS) y la segunda para el cuestionario en línea.

\subsection{Análisis de redes sociales}

En los últimos años la teoría para el análisis de las redes sociales ha cobrado relevancia debido a la forma dominante de la organización social actual. De acuerdo a esta teoría, los integrantes de la red se representan con nodos unidos a otros nodos mediante lazos. El conjunto de nodos conforma la base de la red (Wasserman y Faust, 2013). Una colectividad es estructuralmente cohesiva en la medida en que las relaciones sociales de sus miembros la mantienen unida (Moody y White, 2003:6). Para visualizar las relaciones se utilizan programas informáticos (Sanz, 2003). En el presente estudio se utilizó el ARS para conocer los vínculos que existen entre los internautas y el colectivo \#YoSoy132. El trabajo de campo se llevó a cabo durante los meses de septiembre, octubre, noviembre y diciembre de 2014 (ver Tabla 1). La selección de esta red se debió a dos factores: por ser el principal espacio de actividad política del grupo observado y por la facilidad que ofrece la plataforma para segmentar los temas en tres formas de participación -compartir contenidos (retuit), dando favorito y publicando comentarios (tuits). Fue utilizada la aplicación Twitonomy para registrar la actividad de los participantes. Para conocer la cohesión de la red, es decir, la centralidad y la cercanía de los nodos con otros nodos se tomaron en cuenta sólo aquellos que tuvieron cinco o más conexiones con los mensajes publicados por el colectivo. En cuatro meses se contabilizaron 846 tuits.

Tabla 1. Tuits recolectados

\begin{tabular}{lcccc}
\hline Mes & Tuits & Retuits & Favoritos & Conexiones \\
\hline Septiembre & 125 & 6641 & 2437 & 5762 \\
Octubre & 221 & 14928 & 4912 & 7320 \\
Noviembre & 329 & 42629 & 12973 & 20701 \\
Diciembre & 171 & 34857 & 9841 & 6770 \\
Total & 846 & 99055 & 30163 & 40553 \\
\hline
\end{tabular}

Fuente: Elaboración propia

De cada uno de los mensajes publicados se realizó una minería de datos de los perfiles que participaron. La información se recolectó en una tabla de Excel. Los tuiteros se identificaron por el nombre como usuarios: una arroba seguida de una palabra que los describía. En la minería de datos, sólo se copiaron los perfiles con arroba y no el nombre de los usuarios. Por ejemplo, de un internauta con el perfil @morfeo $2000 \mathrm{mx}$, sólo se registró su denominación como usuario y no como persona. Con la finalidad de proteger la privacidad de los internautas fueron cambiados los apelativos de los perfiles recolectados por un identificador conformado por la palabra "usuario" seguida de la primera letra del nombre en mayúscula y la última letra en minúscula. Cada perfil capturado se relacionó con la 
forma de conexión que estableció con el colectivo. La configuración de la red generó un sesgo en la recopilación de los nombres: en el caso de los retuits y favoritos la red sólo permitió ver un máximo de 125 participantes. Así por ejemplo el 20 de noviembre de 2014 el colectivo difundió a las 18:21 horas el siguiente tuit: "¿Cómo actuar ante una detención arbitraria? \#YaMeCansé \#AcciónGlobalporAyotzinapa". El mensaje fue compartido por 182 usuarios. Sólo se visibilizaron 125 perfiles y 57 permanecieron ocultos. Durante el periodo de análisis se registraron todos los usuarios visibles.

La base de datos con los nombres de los perfiles recolectados fue ingresada al software Frequent List (FrqList) con el fin de hacer un listado de frecuencias y de la distribución de nombres de cada usuario. Posteriormente las frecuencias se analizaron mediante el programa TI for Co-Word Analysis. El TI generó una matriz de palabras de los nombres por ocurrencia de palabras, co-ocurrencia de palabra y co-ocurrencia normalizada. Posteriormente, por cada mes se obtuvo una matriz de palabras que se ingresó al programa Pajek para construir la red de vínculos entre los perfiles y el colectivo. Los perfiles se representaron con nodos y sus vínculos con lazos o ligas. Mediante Pajek se realizaron tres tipos de análisis a partir de la centralidad, es decir, la contribución de un nodo según su ubicación en un sistema: las redes de los nodos con más presencia por mes, el grado de centralidad de los nodos y la distancia entre los nodos más recurrentes con los vecinos más cercanos. Para la elaboración de las redes fueron seleccionados los usuarios que tuvieron más de cinco conexiones en los temas difundidos por el colectivo.

\subsection{Cuestionario en línea}

En lo que se refiere al cuestionario en línea a través de la aplicación SurveyMonkey se diseñó un instrumento que incluyó una breve presentación sobre su finalidad. El nombre de la herramienta fue Internet y participación social. El cuestionario fue aplicado en un intervalo del 24 de marzo al 24 de abril del año 2015 mediante el sitio https://es.surveymonkey.com/s/internet_y_participacion. Para la recolección de datos fueron enviadas más de 4 mil invitaciones personalizadas a seguidores del colectivo en Twitter. Durante el periodo en el cual el cuestionario estuvo abierto se tuvo un registro de 445 participantes. El estudio presentó dos sesgos: a) los resultados no son representativos de la población, toda vez que se desconoce el universo de usuarios que utilizan en México las redes sociales para la participación política; y b) debido a que la selección de los encuestados no fue aleatoria, el margen de confiabilidad es menor que en estudios muestrales. Sin embargo, se considera que el presente ejercicio se valida por el hecho de que interesan, justamente, los internautas que son activos en la red y en escenarios sociales. Son ellos quienes voluntariamente acudieron a participar en la encuesta. Así pues, si bien no se tiene el dato sobre la proporción que ellos ocupan en la población total, su actividad en el estudio coindice con la 
característica central que busca describir el mismo. Esta descripción se suma al trabajo empírico del que da cuenta el presente texto.

Las preguntas del instrumento se elaboraron siguiendo un orden determinado por campos temáticos que son descritos más adelante. Fueron utilizadas tres tipos de preguntas: cerradas dicotómicas -con la opción de dos respuestas-, cerradas categorizadas -con una serie de alternativas de respuesta- y cerradas numéricas -la respuesta se expresó a través de un número, por ejemplo 1, 2, 3, etcétera-. En la formulación de las preguntas se emplearon preguntas de batería -complementan información que fue preguntada previamente- y de evaluación -requieren una respuesta jerarquizada-. El número total de reactivos fue de 25. Cada reactivo formó parte de seis campos temáticos: campo de información general -preguntas 1, 2, 3 y 4-; campo de conectividad -preguntas 5,6 y 8-; campo de información 7 y 9; campo valorativo -preguntas $10,11,12,13$ y 25; campo político -preguntas $14,15,16,17,18,19$ y 20; y campo de participación política-preguntas 21,22 , 23 y $24-$

\section{Resultados del análisis de redes}

\subsection{Vínculos comunicativos de los usuarios de Twitter}

Durante los meses de observación @YoSoy132 publicó 846 contenidos. Los mensajes recibieron en total 99 mil 55 retuits y fueron marcados como favoritos en 30 mil 163 ocasiones. Al finalizar la recolección de información se obtuvieron los siguientes datos: 40 mil 533 conexiones -retuits, favoritos y comentarios- y 23 mil 561 participantes -usuarios que establecieron algún tipo de vínculo con los mensajes compartidos por el colectivo-. En promedio al día 177 personas participaron en los temas difundidos. En lo que se refiere al mes de septiembre se recopilaron 3 mil 279 perfiles que mantuvieron algún modo de conexión. 81 usuarios establecieron más de cinco formas de vínculos con los mensajes difundidos por el colectivo. Mediante el algoritmo de centralidad de grado se encontraron los nodos con el mayor número de enlaces con otros nodos. De los 81 perfiles seleccionados los que registraron más enlaces fueron @UsuarioAn, @UsuarioGs, @UsuarioGl, @UsuarioLs y @UsuarioEo. A través de una medida de cercanía para calcular el promedio de las distancias más cortas desde un nodo hacia todos los demás, se descubrió que cinco usuarios presentaron los mayores niveles de centralidad con valores aritméticos que oscilaron entre 0.8180 y 0.9639 ; siete nodos se ubicaron entre los valores 0.8180 y $0.6722 ; 68$ nodos entre 0.6722 y 0.5263 , y uno, con valor menor a 0.5263 . A mayor valor aritmético fue más la centralidad del nodo. A través de una partición en Pajek se calculó la centralidad de los vecinos o k-neighbours: medición de la distancia más corta entre un nodo y los nodos más cercanos, llamados vecinos. Fueron seleccionados ocho perfiles que aparecieron recurrentemente. A continuación, se presenta en orden de importancia de centralidad los resultados obtenidos que muestran la relación -frecuencia- del nodo seleccionado con el resto de los 80 nodos. 
Tabla 2. Nivel de centralidad en septiembre

\begin{tabular}{lllll}
\hline Rango & Usuario & Frecuencia & \% Frecuencia & Valor en la red \\
\hline 1 & @UsaurioAn & 78 & 96.2963 & 0.9639 \\
& & & & \\
2 & @UsuarioGs & 69 & 85.1852 & 0.8696 \\
3 & @UsuarioGl & 66 & 81.4815 & 0.8421 \\
4 & @UsuarioLs & 65 & 80.2469 & 0.8333 \\
5 & @UsuarioEo & 65 & 80.2469 & 0.8333 \\
7 & @UsuarioMo & 56 & 69.1358 & 0.7619 \\
12 & @UsuarioJr & 43 & 53.0864 & 0.6612 \\
& & & & \\
16 & & & & \\
& & & & \\
\end{tabular}

Fuente: Elaboración propia

En el mes de octubre se registró la participación de 4 mil 75 usuarios. De los datos recolectados se integró un segmento de 167 usuarios que tuvieron cinco o más formas de conexión. A través del vector de centralidad se encontró que el valor más bajo fue de 0.3524 y el más alto de 0.6860 . El nodo con mayor centralidad fue @UsuarioMo y se ubicó en el primer lugar del rango, en tanto el perfil con menor centralidad fue @UsuarioCe en el lugar 167. Del grupo de 167 perfiles seleccionados 17 usuarios tuvieron la mayor centralidad con valores aritméticos entre 0.5748 y 0.6860 . En un segundo sitio se encontraron 131 perfiles con valores entre 0.4636 y 0.5748 , y en un tercer lugar 19 entre 0.3524 y 0.4636 . En la Tabla 3 se observa el rango de los 17 usuarios con mayor centralidad. Por lo que se refiere a la partición de k-neighbours, fueron seleccionados los siete usuarios recurrentes para determinar su cercanía en la red: @UsuarioMo, @UsuarioAn, @UsuarioGs, @UsuarioEo, @UsuarioAr y @UsuarioSz. 
Tabla 3. Usuarios con centralidad por cercanía

\begin{tabular}{llll}
\hline Rango & Vértice & Valor & Identificador \\
\hline 1 & 3 & 0.6860 & @UsuarioMo \\
2 & 1 & 0.6561 & @UsuarioAn \\
3 & 2 & 0.6484 & @UsuarioJo \\
4 & 5 & 0.6459 & @UsuarioGs \\
5 & 4 & 0.6484 & @UsuarioRs \\
6 & 8 & 0.6312 & @UsuarioEa \\
7 & 7 & 0.6288 & @UsuarioEo \\
8 & 17 & 0.6081 & @UsuarioJu \\
9 & 11 & 0.6014 & @UsuarioGl \\
10 & 21 & 0.5950 & @UsuarioLa \\
11 & 34 & 0.5907 & @UsuarioCn \\
12 & 13 & 0.5907 & @UsuarioRe \\
13 & 12 & 0.5845 & @UsuarioAr \\
14 & 6 & 0.5825 & @UsuarioLy \\
15 & 9 & 0.5828 & @UsuarioSj \\
16 & 30 & 0.5764 & @UsuarioVn \\
17 & 82 & 0.5764 & @UsuarioGg \\
\hline
\end{tabular}

Fuente: Elaboración propia

En lo que concierne al mes de noviembre 145 usuarios de 11 mil 595 registrados fueron los que presentaron mayores niveles de participación. El valor más bajo de centralidad fue de 0.2420, y el más alto de 0.5737. En el rango en el cual se encontraron los 145 nodos se ubicó en primer lugar @UsuarioLs con un valor de 0.5737 y en el último sitio @UsuarioTo con 0.2420. En la medición de centralidad @UsuarioGs, @UsuarioFn, @UsuarioLs, @UsuarioNe, @UsuarioJr y @UsuarioSz fueron los perfiles más recurrentes. En la siguiente tabla se muestra la partición en Pajek para encontrar los k-neighbours: el rango y el número de nodos-frecuenciacon los que se relacionaron.

Tabla 4. Usuarios centrales y vecinos cercanos

\begin{tabular}{lllll}
\hline Rango & Usuario & Frecuencia & \% Frecuencia & Valor en la red \\
\hline 1 & @UsuarioLs & 50 & 34.4828 & 0.5737 \\
2 & @UsuarioFn & 46 & 31.7241 & 0.5625 \\
4 & @UsuarioNe & 32 & 22.0690 & 0.5143 \\
5 & @UsuarioGs & 30 & 20.6897 & 0.5106 \\
& & & & \\
8 & @UsuarioJr & 26 & 17.9310 & 0.4915 \\
13 & @UsuarioSz & 22 & 15.1724 & 0.4816 \\
\hline
\end{tabular}

Fuente: Elaboración propia

Para el mes de diciembre se contabilizó la participación de 4 mil 612 usuarios. 123 perfiles presentaron la mayor conectividad. En cuanto a los valores de la centralidad, el más bajo fue de 0.3361 y el más alto de 0.5865 . El algoritmo de 
medición de la centralidad arrojó como resultado que durante dicho mes 13 usuarios mantuvieron mayores vínculos con el resto de los nodos (ver Tabla 5). Tales usuarios generaron valores de relación entre los 0.5031 y 0.5865 puntos. En un segundo nivel se ubicaron 93 perfiles con valores entre 0.4196 y 0.5031 ; y en tercero 16 con 0.3361 y 0.4196 .

Tabla 5. Usuarios con mayor centralidad durante diciembre

\begin{tabular}{llll}
\hline Rango & Vértice & Valor & Identificador \\
\hline 1 & 1 & 0.5865 & @UsuarioEh \\
2 & 5 & 0.5596 & @UsuarioAr \\
3 & 2 & 0.5571 & @UsuarioMo \\
4 & 4 & 0.5545 & @UsuarioLu \\
5 & 11 & 0.5398 & @UsuarioVa \\
6 & 3 & 0.5374 & @UsuarioSz \\
7 & 39 & 0.5214 & @UsuarioLe \\
8 & 16 & 0.5169 & @UsuarioMn \\
9 & 26 & 0.5126 & @UsuarioGm \\
10 & 6 & 0.5105 & @UsuarioFn \\
11 & 25 & 0.5083 & @UsuarioCg \\
12 & 28 & 0.5062 & @UsuarioKp \\
13 & 23 & 0.5062 & @UsuarioMm \\
\hline
\end{tabular}

Fuente: Elaboración propia

A partir de los datos recolectados de cuatro meses de estudio se descubrió la participación reiterativa de cinco usuarios: @UsuarioSz, @UsuarioAr, @UsuarioMo, @UsuarioFn y @UsuarioNe. Con la partición de k-neighbour (ver Tabla 6) se encontró el grado de centralidad de dichos usuarios y los vínculos que mantuvieron con el resto de los nodos.

Tabla 6. Frecuencia de nodos recurrentes

\begin{tabular}{lllll}
\hline Rango & Usuario & Frecuencia & \% Frecuencia & Valor en la red \\
\hline 2 & @UsuarioAr & 30 & 24.3902 & 0.5596 \\
& & & & \\
6 & @UsuarioMo & 28 & 22.7642 & 0.5571 \\
10 & @UsuarioSz & 28 & 22.7642 & 0.5374 \\
14 & @UsuarioFn & 22 & 17.886 & 0.5105 \\
\hline
\end{tabular}

Fuente: Elaboración propia

En el periodo de estudio se encontraron tres tipos de información: la ubicación de los nodos dentro de la red; el grado de centralidad de los nodos con mayor recurrencia en la red y la distancia entre los nodos más recurrentes con sus vecinos más cercanos. En la siguiente tabla se presenta un concentrado de los datos obtenidos a través del grado de centralidad del ARS. 
Tabla 7. Usuarios con mayor centralidad

\begin{tabular}{lccccc}
\hline Mes & $\begin{array}{c}\text { Usuarios } \\
\text { totales }\end{array}$ & $\begin{array}{c}\text { Usuarios } \\
\text { elegidos }\end{array}$ & $\begin{array}{c}\text { Valor más } \\
\text { alto }\end{array}$ & $\begin{array}{c}\text { Valor } \\
\text { más bajo }\end{array}$ & $\begin{array}{c}\text { Usuarios con } \\
\text { más } \\
\text { centralidad }\end{array}$ \\
\hline Septiembre & 3279 & 81 & 0.9639 & 0.5263 & 5 \\
Octubre & 4075 & 167 & 0.6860 & 0.3524 & 17 \\
Noviembre & 11595 & 145 & 0.5737 & 0.2420 & 25 \\
Diciembre & 4612 & 123 & 0.5865 & 0.3361 & 13 \\
Total & 23561 & 516 & 0.7025 & 0.3642 & 60 \\
\hline
\end{tabular}

Fuente: Elaboración propia.

Por lo que respecta a los perfiles que mostraron presencia recurrente durante el periodo de investigación, los nodos que registraron un mayor número de enlaces con otros nodos fueron: @UsuarioSz, @UsuarioMo, @UsuarioEo, @UsuarioAn, @UsuarioAr, @UsuarioFn, @UsuarioGs,@UsuarioGl, @UsuarioJr, @UsuarioLs y @UsuarioNe. En la Tabla 8 se presenta una recopilación de los resultados encontrados con la partición K-Neighbours, el lugar que ocupan en el rango de la red y la relación que mantienen con sus vecinos. Los nodos recurrentes presentaron extensos lazos que los relacionaron con otros nodos. Por ejemplo, en septiembre @UsuarioAn tuvo relación con 78 vecinos y @UsuarioGs con 69. Para octubre @UsuarioAn se vinculó con 81 y @UsuarioGs con 77. Situación similar presentaron otros nodos recurrentes a lo largo de los cuatro meses observados. Las relaciones de los nodos recurrentes con otros nodos los ubicaron en rangos centrales dentro de la red. La presencia recurrente -relación con vecinos- significo una co-presencia al momento en que @YoSoy132 difundió contenidos en Twitter. 
Tabla 8. Datos concentrados de vecinos

\begin{tabular}{|c|c|c|c|}
\hline Mes & Nodo recurrente & $\begin{array}{c}\text { Relaciones con } \\
\text { vecinos }\end{array}$ & $\begin{array}{l}\text { Rango } \\
\text { en la red }\end{array}$ \\
\hline \multirow{8}{*}{ Septiembre } & @UsuarioAn & 78 & 1 \\
\hline & @UsuarioGs & 69 & 2 \\
\hline & @UsuarioGl & 66 & 3 \\
\hline & @UsuarioLs & 65 & 4 \\
\hline & @UsuarioEo & 65 & 5 \\
\hline & @UsuarioMo & 56 & 7 \\
\hline & @UsuarioJr & 43 & 12 \\
\hline & $@$ UsuarioSz & 38 & 16 \\
\hline \multirow{7}{*}{ Octubre } & @UsuarioMo & 94 & 1 \\
\hline & @UsuarioAn & 81 & 2 \\
\hline & @UsuarioGs & 77 & 4 \\
\hline & @UsuarioEo & 70 & 7 \\
\hline & @UsuarioGI & 62 & 9 \\
\hline & $@$ UsuarioAr & 54 & 13 \\
\hline & $@$ UsuarioSz & 46 & 19 \\
\hline \multirow{6}{*}{ Noviembre } & @UsuarioLs & 50 & 1 \\
\hline & @UsuarioFn & 46 & 2 \\
\hline & @UsuarioNe & 32 & 4 \\
\hline & @UsuarioGs & 30 & 5 \\
\hline & @UsuarioJr & 26 & 8 \\
\hline & $@$ UsuarioSz & 22 & 13 \\
\hline \multirow{5}{*}{ Diciembre } & $@$ UsuarioAr & 30 & 2 \\
\hline & @UsuarioMo & 28 & 3 \\
\hline & @UsuarioSz & 28 & 6 \\
\hline & @UsuarioFn & 22 & 10 \\
\hline & @UsuarioNe & 24 & 14 \\
\hline
\end{tabular}

Fuente: Elaboración propia

Mediante un ARS se construyó una red con los once usuarios que aparecieron recurrentemente durante el periodo de análisis. En la siguiente red se visualizan los vínculos entre los usuarios presentes en los cuatro meses de estudio, así como entre los usuarios con otros usuarios (ver Figura 1). La red muestra también, aquellos usuarios que aparecen como puentes entre usuarios en otros meses. Los resultados permitieron conocer que los nodos recurrentes fueron también copresentes de los mensajes difundidos en la red observada y tal característica les permitió al mismo tiempo ser puentes entre los nodos participantes. 


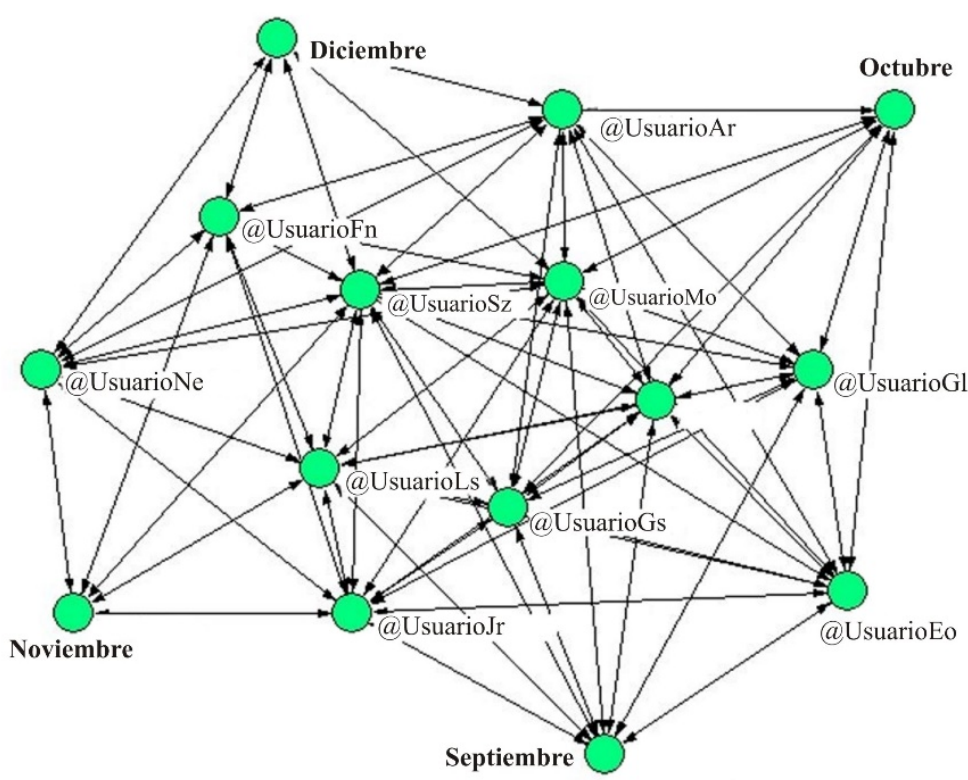

Figura 1. Lazos entre los 11 usuarios más recurrentes

Fuente: elaboración propia

\subsection{Percepciones de los internautas}

En lo que respecta al cuestionario aplicado a seguidores del colectivo \#YoSoy132, la mayoría de los cibernautas que respondieron el instrumento fueron personas jóvenes adultas con edades entre los 25 y 44 años de edad (ver Tabla 9). Las preguntas 1, 2, 3 y 4 se diseñaron para obtener información general sobre los cibernautas. De la muestra, el $55.33 \%$ fueron mujeres y el $44.67 \%$ fueron hombres. En cuanto a la situación ocupacional el $58.86 \%$ de la muestra aseguró tener un trabajo fijo, el $11.82 \%$ estudia y el $24.77 \%$ trabaja y estudia. A la pregunta sobre el último grado académico el $46.71 \%$ tiene estudios de posgrado, el $37.19 \%$ licenciatura, el $12.24 \%$ preparatoria, el $2.49 \%$ secundaria, el $0.91 \%$ primaria y el $0.45 \%$ no tiene estudios concluidos. 
Tabla 9. Edades de las personas encuestadas

\begin{tabular}{lc}
\hline \multicolumn{1}{c}{ Edades } & Porcentaje \\
\hline Menos de 11 años & $0.45 \%$ \\
De 12 a 17 años & $3.16 \%$ \\
De 18 a 24 años & $13.09 \%$ \\
De 25 a 34 años & $37.02 \%$ \\
De 35 a 44 años & $29.80 \%$ \\
De 45 a 54 años & $11.96 \%$ \\
Más de 55 años & $4.51 \%$ \\
\hline
\end{tabular}

Fuente: Elaboración propia

Las preguntas $5,6,7,8$ y 9 se relacionaron con el campo de la conectividad del usuario. El $47.18 \%$ aseguró pasar más de cinco horas al día en la red; el $14.90 \%$ de cuatro a cinco horas; el $15.35 \%$ de tres a cuatro horas; el $4.74 \%$ de dos a tres horas y el $1.81 \%$ menos de una hora. Respecto a las principales actividades que realizan los usuarios de internet, el 20.20\% lo emplea para asuntos de trabajo; el $19.9 \%$ para enviar y recibir mensajes instantáneos; el $19.59 \%$ para consultar noticias y estar informado; el $15.52 \%$ para compartir información en las redes sociales; el $9.35 \%$ para ver videos y escuchar música; el $7.25 \%$ para realizar tareas escolares; el $4.40 \%$ para opinar sobre asuntos que son de interés y el $2.23 \%$ para comprar en línea. En la respuesta "otras" se presentaron 22 comentarios correspondientes al 1.4\%. Algunos ejemplos de las respuestas fueron "realizar operaciones bancarias", "encontrar pareja", "para leer libros digitales", "para leer cuentos, libros, historias de temática libre", "transmisión de datos" y "participar en la vida política y social del país".

Respecto a la red sociodigital más utilizada, los datos obtenidos demostraron que Facebook fue la plataforma más popular: el $75.29 \%$ tienen perfil en dicha red. Le siguen en popularidad Twitter con el 12.94\%; Google + con $3.76 \%$ e Instagram con $0.94 \%$. El $6.59 \%$ de las personas respondieron usar otra red, entre las que destacaron tres opciones: WhatsApp, Tumblr y Xing. Se cuestionó a los internautas sobre la frecuencia del uso de medios tradicionales y de nuevos medios conectados a internet con la finalidad de mantenerse informados sobre lo que ocurre en su comunidad y en el país. Cada medio contó con cinco tipos de respuesta ordenados en escala: siempre, casi siempre, algunas veces, rara vez y nunca. La Tabla 10 muestra los datos encontrados. Entre los hallazgos destacó el uso frecuente de internet como medio de información (49.34\%) y la consulta de páginas web (40.34\%). Los nuevos medios superaron en usabilidad a los medios tradicionales: periódicos (25\%), radio (18.27\%) y televisión (15.33\%). 
Tabla 10. Frecuencia del uso de medios para informarse

\begin{tabular}{lccccc}
\hline Medio & Siempre & Casi siempre & Algunas veces & Rara vez & Nunca \\
\hline Televisión & $16.33 \%$ & $18.73 \%$ & $35.04 \%$ & $24.33 \%$ & $6.57 \%$ \\
Radio & $18.27 \%$ & $20.26 \%$ & $29.63 \%$ & $23.95 \%$ & $7.90 \%$ \\
Periódicos & $25 \%$ & $24.75 \%$ & $25.98 \%$ & $17.16 \%$ & $7.11 \%$ \\
Revistas & $4.55 \%$ & $14.21 \%$ & $28.42 \%$ & $32.82 \%$ & $19.90 \%$ \\
Redes sociales & $49.34 \%$ & $35.82 \%$ & $10.10 \%$ & $4.09 \%$ & $0.48 \%$ \\
Páginas web & $40.34 \%$ & $39.61 \%$ & $14.18 \%$ & $5.13 \%$ & $0.73 \%$ \\
\hline
\end{tabular}

Fuente: Elaboración propia

Sobre el tipo de información que más consultan los usuarios, el principal tema fue el político (20.34\%). Le siguen cultura (15.95\%); educación (14.48\%); tecnología (13.53\%); música (11.56\%); deportes (5.98\%); medio ambiente (5.37\%); comida (5.10\%); moda (5.03\%) y otros tópicos (2.72\%). Como ejemplos de otros temas se encontraron "compra-venta", "manualidades", "belleza", "negocios", "salud", "literatura", "economía", "violencia y crimen", "fotografía", "divisas", "viajes", "diseño" y "periodismo". En el grupo de preguntas 10, 11, 12 y 13, se buscó obtener datos sobre lo que representa internet para los encuestados (ver Tabla 11). Destacaron dos datos: el $55.74 \%$ aseguró que internet es importante porque es un medio que los mantiene informados y el $23.89 \%$ porque a través de la red se pueden comunicar con otras personas. En la opción "otro", fueron registradas 23 respuestas, entre las que se encontraron: "herramienta de trabajo", "un medio de intercambio de información", "trabajo y entretenimiento", "acceso a otras culturas" y "un medio de comunicación polifuncional".

Tabla 11. Significados que tiene internet

\begin{tabular}{ll}
\hline \multicolumn{1}{c}{ Definición } & Porcentaje \\
\hline Un lugar de entretenimiento & $6.56 \%$ \\
Un medio para mantenerme informado & $55.74 \%$ \\
Una zona pública para expresar mis ideas & $6.09 \%$ \\
Un espacio para comunicarme con otros & $23.89 \%$ \\
Un sitio para debatir mis ideas & $2.11 \%$ \\
Un canal para manifestar inconformidades & $0.23 \%$ \\
Otros significados & $5.38 \%$ \\
\hline
\end{tabular}

Fuente: Elaboración propia

Mediante un diseño dicotómico se cuestionó a los participantes si consideraban a internet como un espacio abierto para expresar sus ideas. El $86.85 \%$ aseguró que sí y el $13.15 \%$ respondió que no. Siguiendo el tema de la libertad, a los internautas se les preguntó qué harían si un contacto en sus redes sociales publicara algún comentario que fuera en contra de su manera de pensar. Los resultados fueron: ignoro el comentario (38.85\%); escribo un comentario sin ofender, pero aclaro que no estoy de acuerdo (35.97\%); debato (15.59\%); oculto o 
elimino el comentario (3.12\%); denuncio el mensaje ante la red social $(0.72 \%)$ y bloqueo al usuario (1.68\%). En cuanto a otras opciones, se recolectaron 17 respuestas. Algunos ejemplos: "lo tomo en cuenta", "si hay condiciones para el intercambio de ideas, lo hago, si no lo omito", "depende de qué tan cercano sea el contacto", "debato vía inbox", "pienso en contestarle, pero me contengo", "trato de indagar más sobre él antes de eliminarlo", "solamente lo leo" y "no hago nada". Se les pidió a los encuestados que en una escala de ordenación eligieran a través de un número las características que consideraran más importantes sobre la comunicación en internet, donde 1 representó más importante y 5 menos importante (ver Tabla 12). Las respuestas más relevantes fueron: "la facilidad para encontrar información"; "la rapidez de la comunicación"; "el acceso a contenidos muy diversos"; "la posibilidad de compartir contenidos con los demás" y "el permitirme comunicarme mediante el anonimato".

Tabla 12. Importancia de la comunicación en internet

\begin{tabular}{llllll}
\hline $\begin{array}{l}\text { Facilidad } \\
\text { para } \\
\text { encontrar } \\
\text { información }\end{array}$ & $\begin{array}{l}\text { Permitir } \\
\text { comunicarme } \\
\text { mediante el } \\
\text { anonimato }\end{array}$ & $\begin{array}{l}\text { Posibilidad } \\
\text { de } \\
\text { compartir } \\
\text { contenidos } \\
\text { con los } \\
\text { demás }\end{array}$ & $\begin{array}{l}\text { La rapidez de } \\
\text { la } \\
\text { comunicación }\end{array}$ & $\begin{array}{l}\text { El acceso a } \\
\text { contenidos } \\
\text { muy diversos }\end{array}$ \\
\hline $\mathbf{1}$ & $41.08 \%$ & $7.06 \%$ & $8.69 \%$ & $27.59 \%$ & $15.93 \%$ \\
2 & $24.88 \%$ & $8.00 \%$ & $21.36 \%$ & $25.94 \%$ & $20.14 \%$ \\
3 & $19.48 \%$ & $5.41 \%$ & $32.39 \%$ & $20.99 \%$ & $22.01 \%$ \\
4 & $10.80 \%$ & $11.53 \%$ & $30.75 \%$ & $21.23 \%$ & $25.76 \%$ \\
5 & $3.76 \%$ & $68.00 \%$ & $6.81 \%$ & $4.25 \%$ & $16.16 \%$ \\
\hline
\end{tabular}

Fuente: Elaboración propia

En las preguntas sobre el campo político - de la 14 a la 20- a los encuestados se les cuestionó ¿En tu opinión, para qué sirve la democracia? El instrumento ofreció a los encuestados seis opciones de respuesta. Los resultados fueron: $29.50 \%$ indicó que la democracia sirve para participar en las decisiones del gobierno; $23.50 \%$ para vivir en una sociedad libre; $16.75 \%$ para elegir a los gobernantes; 7.75\% para que no exista desigualdad; $7.50 \%$ para acudir a votar libremente y $2.75 \%$ para resolver injusticias. En esta pregunta 49 personas escribieron una definición diferente a las opciones presentadas. De dichas opiniones el 63.26\% incluyó connotaciones negativas, por ejemplo: "no existe la democracia", "la democracia es una farsa" o "sirve para controlar a la población". El resto de los comentarios presentaron otro tipo de descripciones, por ejemplo: "para darle voz a todos, para elegir a representantes", "para poder expresar diferentes puntos de vista, aunque no sean respetados en su totalidad" o "para ser partícipes en la forma de ejercer el gobierno".

Otro tema que se midió fue la confianza de la sociedad en la información que publican en internet las instituciones públicas y políticas, los grupos económicos y 
los medios de difusión. Se les pidió a las personas que otorgaran una calificación numérica donde 1 significó nada de confianza y 10 absoluta confianza. El mayor nivel de confianza lo obtuvieron las organizaciones civiles con 6.87 puntos, en segundo nivel los periódicos con 5.90 y en tercer sitio la radio con 5.84. Siguieron en orden descendente las empresas privadas (5.32); el ejército (4.78); la iglesia (4.54); la televisión (4.10); los sindicatos (4.06); los gobiernos (3.95); los partidos políticos (3.25) y los representantes sociales o legisladores (3.21).

En cuanto a la influencia de las nuevas tecnologías de la información sobre lo político, se preguntó a los internautas si creían que con el uso de internet y las redes sociodigitales se podría tener injerencia sobre las políticas del Estado. El 86.47\% aseguró que las persona que utilizan la red tienen más oportunidades para influir en las decisiones del gobierno. Se cuestionó a los internautas ¿qué tan seguido acostumbras consultar en internet información sobre política? El 71.63\% respondió consumirla al menos una vez al día; el $20.91 \%$ al menos una vez a la semana; el $3.13 \%$ al menos una vez al mes; el $2.88 \%$ dijo que nunca; el $0.96 \%$ al menos una vez al año y el $0.48 \%$ al menos una vez cada seis meses. A los internautas se les planteó una interrogante sobre la libertad de la red (ver Tabla 13): ¿consideras que en internet existe mayor libertad que en la vida real para comentar temas políticos? Mediante una escala de respuesta la mayoría de los participantes consideró que existe mayor libertad en la red que en la vida real.

Tabla 13. Libertad para comentar temas políticos en internet

\begin{tabular}{ll}
\hline \multicolumn{1}{c}{ Opciones de respuesta } & Porcentaje \\
\hline Muy de acuerdo & $42.69 \%$ \\
Algo de acuerdo & $33.57 \%$ \\
Ni de acuerdo ni en desacuerdo & $14.15 \%$ \\
Algo en desacuerdo & $6 \%$ \\
Muy en desacuerdo & $3.60 \%$ \\
\hline
\end{tabular}

Fuente: Elaboración propia

Fue elaborada una pregunta específica para conocer los mensajes políticos que los internautas comparten en internet. Se ofrecieron seis opciones de respuesta: comentarios personales, enlaces, memes, fotografías, videos y ningún mensaje. Los participantes respondieron que la información política que más acostumbran publicar son enlaces a otros contenidos (31.12\%) y comentarios personales (21.4\%). Los internautas también difunden memes (16.3\%); fotografías (14.5\%) y videos (11.0\%). El $58.85 \%$ de los participantes afirmó seguir a algún político a través de las redes sociodigitales. En las preguntas sobre la participación de las personas en acciones colectivas en línea -reactivos del 21 al 25- se pidió a los cibernautas que contestaran la interrogante: ¿participas en internet en alguna organización, asociación, grupo o movimiento civil? El 69.48\% respondió no participar. La pregunta, ¿qué tan fácil o difícil crees que es organizarse en México con otros ciudadanos a través de internet para trabajar en una causa común?, 
arrojó los siguientes datos: algo difícil (34.33\%); fácil (20.40\%); difícil (19.40\%); poco difícil (18.66 \%) y muy difícil (7.21\%).

A través de una lista de opciones se les pidió a los encuestados que señalaran cuáles acciones en línea habían realizado con la finalidad de resolver algún problema personal o colectivo. El $55.20 \%$ aseguró haber publicado mensajes en sus redes sociales; el $38.12 \%$ firmó cartas virtuales de protesta; el $32.43 \%$ se quejó ante autoridades públicas y el $28.47 \%$ denunció hechos mediante el envío de mensajes a medios de difusión tradicionales (ver Tabla 14). El $12.78 \%$ de los encuestados dijo no participar en acciones de este tipo y el $7.6 \%$ seleccionó otras acciones: afiliarse a grupos sociales afines a sus intereses, para localizar a personas extraviadas y para denunciar hechos o delitos. Otra pregunta vinculada a la acción colectiva fue la siguiente: ¿qué motivos crees que limitan la participación de las personas en movilizaciones sociales organizadas por internet? El 28.7\% respondió que la principal limitante es la apatía o indiferencia; el $25.05 \%$ el temor a represalias o venganzas; el $18.5 \%$ el desconocimiento o ignorancia; el $10.8 \%$ la falta de solidaridad; el $4.37 \%$ la carencia de recursos económicos y el $1.5 \%$ las diferencias ideológicas. En la respuesta "otros", se recolectaron diversos motivos: falta de recursos técnicos, falta de conectividad a internet, por analfabetismo tecnológico, por causas de trabajo, por apego a la zona personal de confort, por desconfianza de los organizadores y por falta de cultura de uso de las redes para tales fines.

Tabla 14. Acciones civiles a través de internet

\begin{tabular}{ll}
\hline \multicolumn{1}{c}{ Tipo de acción } & Porcentaje \\
\hline Quejarme con autoridades & $32.43 \%$ \\
Enviar mensajes a medios de comunicación & $28.47 \%$ \\
Organizarme con otras personas para marchas, protestas, etc. & $21.29 \%$ \\
Colocar mensajes en mis redes & $55.20 \%$ \\
Pedir apoyo a organizaciones civiles & $15.84 \%$ \\
Firmar cartas virtuales de protesta & $38.12 \%$ \\
Solicitar ayuda a partidos políticos & $2.48 \%$ \\
Pedir apoyo a legisladores -diputados/senadores- & $6.44 \%$ \\
Enviar correos electrónicos a mis contactos & $32.18 \%$ \\
No he participado en acciones sociales en internet & $19.31 \%$ \\
\hline
\end{tabular}

Fuente: Elaboración propia

Por último, se preguntó a los encuestados ¿en qué situación consideras que internet debe ser regulado? El $43.32 \%$ consideró que la red debe ser regulada cuando se viole la vida privada de las personas; el $10.89 \%$ por motivos de seguridad pública; el $7.18 \%$ para prevenir sicosis; el $7.18 \%$ ante un desorden social y el $5.94 \%$ en casos de explotación de productos sin pago previo de derechos -películas, discos, libros, programas informáticos, etcétera-. La mayoría de las respuestas de los entrevistados se inclinaron a la aprobación de alguna de las hipótesis para regular internet y las redes sociodigitales. En tanto, casi una 
tercera parte de los participantes consideró que la red no debe ser regulada bajo ningún argumento (29.21\%).

Los resultados relacionados al campo general, de conexión y de información coinciden en parte con los hallazgos obtenidos en estudios realizados por algunos organismos en México como la Encuesta Nacional sobre Disponibilidad y Uso de Tecnologías de la Información en los Hogares (2018) del Instituto Nacional de Estadística y Geografía (INEGI) o las investigaciones realizadas por la Asociación de Internet.mx. Sin embargo, los campos valorativo, político y de participación arrojaron nuevos datos sobre la práctica que realizan los usuarios de las redes sociales. El instrumento aplicado puede ser consultado en el apartado anexos que se encuentra al final del presente trabajo.

\section{Conclusiones}

El presente estudio muestra los hallazgos de investigación sobre las nuevas formas de acción colectiva en red y la percepción política que tienen los usuarios. La culminación del estudio puede sintetizarse en dos puntos: las características de la emergente forma tecnopolítica generada por la comunicación en red y los significados sobre lo político a partir de la práctica tecnológica. El espacio público en internet es un lugar abierto para la interacción social y la comunicación política. Twitter es una red social que facilita la circulación de asuntos públicos y la participación de los internautas en temas políticos compartidos por colectivos. Como plantean diversos autores, la actividad comunicativa observada fue horizontal: todos podían comunicarse con todos. Sin embargo, se pudo apreciar que tal participación quedó supeditada al diseño tecnológico, es decir, las personas pudieron llevar a cabo diversas acciones pero bajo ciertas limitantes: compartir el contenido, marcarlo como favorito o publicar un comentario no mayor a determinados caracteres. Asimismo, se descubrió la presencia recurrente de usuarios que dieron centralidad a la red. Esto significa que los participantes más activos son quienes dan cohesión a una colectividad en línea al mantener cercanía con otros perfiles y co-presencia al momento en que son difundidos los contenidos. En este sentido el modo de comunicación en la red presentó cierta jerarquía. Los usuarios con mayor actividad se colocaron en posiciones claves para la comunicación del colectivo. Esta ubicación puede definirse como heterárquica en cuanto al lugar central que ocupa el usuario en la red y su capacidad para la interacción y distribución de contenidos (ver Tabla 15). Estos nuevos niveles analizados dentro de la actividad colectiva son los que dan cierta solidez a la red. A partir del caso estudiado, se puede afirmar que la posibilidad de comunicación individualizada y la heterarquía forman parte de los rasgos que identifican las cambiantes formas de participación política mediante el uso tecnológico. 
Tabla 15. Características de la comunicación política en red

\begin{tabular}{cc}
\hline Horizontalidad & Heterarquía \\
\hline Participación a través de las TIC & Participación a través de las TIC \\
Comunicación omnidireccional & Cohesión mediante la participación \\
Posición en el mismo nivel de la red & Posición en nivel jerárquico de la red \\
\hline
\end{tabular}

Fuente: Elaboración propia

En lo que respecta a los significados que otorgan los individuos a lo político, mediante un cuestionario en línea se descubrió que la mayoría de los participantes son personas jóvenes que estudian o ejercen alguna profesión. La edad y el nivel de escolaridad son peculiaridades que sobresalen en la politización de colectivos en internet. La forma de participación política en red estuvo relacionada con la publicación de mensajes, la firma de cartas electrónicas y el envío de correos a sus contactos. Existe una mayor libertad de acción colectiva en internet que en la vida real. En este nuevo espacio público las personas comentan más de política que en los espacios físicos. En esta tesitura, los usuarios cuentan con canales amplificados de información y se comunican directamente con los actores políticos sin intermediarios. Además, existe entre los cibernautas la creencia de que la red puede influir sobre las políticas de los gobiernos, aunque la mayoría no está afiliado a alguna organización civil o política. Para los usuarios de la nueva tecnología la democracia necesita que las personas participen en las decisiones de las autoridades. Conciben a internet como un espacio abierto para expresar sus ideas y por lo tanto las expresiones políticas no deben ser reguladas. La sociedad en línea dejó de acudir a lugares tradicionales de denuncia-como las contralorías o los tribunales- para montar sus demandas en la plaza-red. Esto se debe a la gran desconfianza que tienen las personas en las instituciones públicas y los actores políticos y al elevado nivel de mediatización que tiene la política en la sociedad actual. Aunque en las redes los usuarios son seguidores de políticos, partidos y gobiernos, la mayoría desconfía de la comunicación política generada por los grupos de poder.

Los datos obtenidos permiten explorar sobre los cambios que experimentan los colectivos que llevan a cabo diversas acciones mediante la tecnopolítica: la comunicación politizada en las redes sociodigitales y las percepciones que los usuarios tienen de lo político. La investigación arrojó información empírica sobre la manera en la cual se construye una red entorno a un colectivo que funciona como espacio de denuncia y exposición de asuntos públicos. Para que las exigencias sean del conocimiento de la sociedad la libertad de un colectivo ya no depende sólo de tecnopolítica. Su funcionamiento como acción colectiva también corresponde a factores motivados por la individualidad. La participación activa de los internautas determina en gran medida la visibilidad de los asuntos demandados por los grupos sociales. Tal visibilidad está condicionada a su vez por la cercanía que exista entre los integrantes, la presencia recurrente y la copresencia durante los hechos políticos. En los espacios en línea lo político se 
configura a partir de las experiencias de libertad de los usuarios y de las prácticas que llevan a cabo con la tecnología. Es posible afirmar desde una visión constructivista que los internautas otorgan significado político a los aparatos que utilizan para realizar variadas actividades politizadas. Las redes son esenciales para la libertad de opinión de la sociedad, para informarse sobre asuntos públicos y para participar en actividades políticas a distancia. Los resultados permitirán continuar indagando sobre el rol que juegan las redes como modos de acción colectiva y de comunicación política, como espacios para la interacción entre los integrantes de grupos y como escenarios donde se manifiestan nuevos hábitos políticos. 
- Sergio Octavio Contreras Padilla

\section{Referencias bibliográficas}

ABBATE, J. (2008). Internet: su evolución y sus desafíos, en GANDARIAS, C. (Ed.): Fronteras del Conocimiento. Madrid, BBVA, pp.143-153.

ADAME, J. (2015): Ciudadanía digital: ¿oportunidad o amenaza? México, Imagia Comunicación.

ALONSO, J. (2013): Cómo escapar de la cárcel de lo electoral: el Movimiento \#YoSoy132. Desacatos, n. 42, pp. 17-40.

ANDUIZA, E., CANTIJOCH, M., GALLEGO, A. y SALCEDO, J. (2010): Internet y participación política en España. Madrid, Centro de Investigaciones Sociológicas.

ANDUIZA, E., CRISTANCHO, C. y CANTIJOCH, M. (2012): La exposición a información política a través de internet. ARBOR Ciencia, Pensamiento y Cultura, 188 (756), pp. 673-688.

ARDITI, B. (1995): Rastreando lo político. Revista de Estudios Políticos, n. 87, pp. 333-351.

ARENDT, H. (1996): Entre el pasado y el futuro. Ocho ejercicios sobre la reflexión política. Barcelona, Península.

BACALLAO-PINO, L. (2016): Redes sociales, acción colectiva y elecciones: los usos de Facebook por el movimiento estudiantil chileno durante la campaña electoral de 2013. Palabra Clave, 19 (3), pp. 810-837.

BELL, D. (1991): El advenimiento de la sociedad post-industrial. Madrid, Alianza Editorial.

BEN-JELLOUN, T. (2011): Primavera Árabe: el despertar de la dignidad. España, Alianza Editorial.

BOBBIO, N. (1986): El futuro de la democracia. México, Fondo de Cultura Económica.

BONILLA, I. (2002): ¿De la plaza pública a los medios? Signo y pensamiento, 21 (41), pp. 82-89.

CAl, Y. (2016): The occupy movement in Hong Kong: sustaining decentralized protest. London, Imprint Routledge.

CALLON, M. y LAW, J. (1989): On the Construction of Sociotechnical Networks: Content and Context Revisited. Knowledge and Society, n. 9, pp. 57-83. 
CANEL, M. (2006): Comunicación Política. Guía para su estudio y práctica. Madrid: Tecnos.

CARDOSO, G. (2010): Los medios de comunicación en la sociedad red. Filtros, escaparates y noticias. Barcelona, UOC.

CASTAÑEDA, E. (2012): The Indignados of Spain: A Precedent to Occupy Wall Street. Social Movement Studies, 11 (3-4), pp. 309-319.

CASTELLS, M. (1997): La era de la información. Volumen 1. Madrid, Alianza Editorial.

(2010): Comunicación y Poder. Madrid, Alianza Editorial.

(2012): Redes de indignación y esperanza. Madrid, Alianza Editorial.

CELORIO, M. (2011): Internet y dominación. Hacia una sociología de la nueva espacialidad. México, Plaza y Valdés Editores.

COHEN, R. y RAl, S. (2000): Global Social Movements. New York, The Athlone Press.

COLINA, C. (2005): Ciudades mediáticas. Caracas, Universidad Central de Venezuela.

DIJK, V. (2006): La sociedad red: aspectos sociales de los nuevos medios. Londres, Sage Publications.

DOMínGUEZ, J., GREENE, K., LAWSON, C. y MORENO, A. (2015): Mexico's envolving democracy: a comparative study of the 2012 elections. Baltimore, Johns Hopkins University Press.

ELSTER, J. (2001): La democracia deliberativa. Barcelona, Gedisa.

FILLIEULE, O. y TARTAKOWSKY, D. (2015): La manifestación. Cuando la acción colectiva toma las calles. Argentina, Editorial Siglo XXI.

FLOWERDEW, J. y JONES, R. (2016): Occupy Hong Kong: historicizing protest. Journal of Language and Politics, 15 (5), pp. 519-526.

FUNES, M. y MONFERRER, J. (2003): Perspectivas teóricas y aproximaciones metodológicas al estudio de la participación, en FUNES, M. y ADELL, R. (Ed.): Movimientos Sociales: Cambio Social y Participación. Madrid, Editorial UNED, pp. $1-42$. 
GAGO, R. (2019): Ciberfeminismo en España: discurso teórico y prácticas digitales. Alicante, Avicam Ediciones.

GÓMEZ, R. y TRERÉ, E. (2014): The \#YoSoy132 movement and the struggle for media democratization in Mexico. Convergence: The International Journal of Research into New Media Technologies, 20 (4), pp. 496-510.

GROSSMAN, L. (1995): The electronic republic: Reshaping democracy in the information age. New York, Viking.

GUTIÉRREZ, I. (2017): Las revoluciones árabes: relato de un proceso de desarrollo. Madrid, Editorial Síntesis.

HABERMAS, J. (1986): Historia y crítica de la opinión pública. México, Gustavo Gilli.

(1999): Teoría de la acción comunicativa: racionalidad de la acción y racionalización social. España, Taurus.

HAYTHORNTHWAITE, C. (2012): Democratic process in online crowds and communities. Journal of Democracy, 4 (2), pp. 160-170.

HILL, K. y HUGHES, J. (1998): Cyberpolitics: Citizen activism in the age of the internet. Maryland, Rowman and Littlefield.

HINE, C. (2004): Etnografía virtual. Barcelona, Editorial UOC.

HUGHES, T. (1983): Networks of Power: Electrification in Western Society, 18801930. Baltimore, John Hopkins University Press.

JIMÉNEZ, M. y RAMÍREZ, J. (2010): La acción colectiva y los movimientos sociales campesinos en América Latina. Interciencia, 35 (9), pp. 704-708.

KARAGIANNOPOULOS, V. (2018): Living with hacktivism. Switzerland, Palgrave Macmillan.

KATZ, J. y RICE, R. (2005): Consecuencias sociales del uso de internet. Barcelona, UOC.

KAVADA, A. (2015): Creating the collective: social media, the Occupy Movement and its constitution as a collective actor. Information, Communication \& Society 18 (8), pp. 872-886.

KERCKHOVE, D. (2009): Inteligencia en conexión: hacia una sociedad de la web. Barcelona, Gedisa. 
KURBAN, C., PEÑA-LÓPEZ, I. y HABERER, M. (2017): What is technopolitics? A conceptual schema for understanding politics in the digital age. Revista de Internet, Derecho y Política, n. 24, pp. 3-20.

KWAK, N., LANE, D., WEEKS, B., HEE, D., LEE, S. y BACHLEDA, S. (2018): Perceptions of social media for politics: testing the slacktivism hypothesis. Human Communication Research, 44 (2), pp. 197-221

LI, J. (2016): The techno-politics of the wall. En LOBATO, R. y MEESE, J. (Ed.): Geoblocking and global video culture. Amsterdam, Institute of Network Cultures, pp. 110-119.

LOGAN, R. (2010): Understanding New Media: Extending Marshall McLuhan. New York, Peter Lang Publishing.

LÓPEZ, G., GAMIR, J. y VALERA, L. (2018): Comunicación política, teorías y enfoques. Madrid, Síntesis.

LUBIN, J. (2012): The Occupy Movement: emerging protest forms and contested urban spaces. Berkeley Planning Journal, 25 (1), pp. 184-197.

MACKENZIE, D. y WAJCMAN, J. (1985): The Social Shaping of Technology. Buckingham, Open University Press.

MASUDA, Y. (1984): La sociedad informatizada como sociedad post-industrial. Madrid, Fundesco Tecnos.

MCADAM, D., TARROW, S. y TILLY, C. (2001): Dinámica de la contienda política. Barcelona, Editorial Hacer.

MELUCCI, A. (1996): Challenging codes: collective action in the information age. Cambridge, Cambridge University Press.

MONGE, C. (2017): 15M un movimiento político para democratizar la sociedad. Zaragoza, Prensas de la Universidad de Zaragoza.

MOODY, J. y WHITE, D. (2003): Structural cohesion and embeddedness: a hierarchical concept of social groups. American Sociolical Review, 1 (68), pp. 103127.

OLESEN, T. (2015): Global Injustice Symbols and Social Movements. Nueva York, Palgrave. 
OLSON, M. (1992): La lógica de la acción colectiva, bienes públicos y la teoría de grupos. México, Limusa.

PEÑA-LÓPEZ, I., CONGOSTO, M. y ARAGÓN, P. (2014): Spanish Indignados and the evolution of the $15 \mathrm{M}$ movement on Twitter: towards networked parainstitutions. Journal of Spanish Cultural Studies, 15 (1-2), pp. 189-216.

PLEYERS, G. (2018): Movimientos sociales en el siglo XXI. Buenos Aires, CLACSO.

PRIEGO, A. (2011): Primavera árabe: ¿una cuarta ola de democratización? Res Pública: Revista de Filosofía Política, n. 30, pp. 147-162.

RABOTNIKOF, N. (2006): En busca de un lugar común. El espacio público en la teoría política contemporánea. México, Instituto de Investigaciones FilosóficasUNAM.

RASH, W. (1997): Politics on the nets: Wiring the political process. New York, W.H. Freeman.

REGUILLO, R. (2017): Paisajes insurrectos. Jóvenes, redes y revueltas en el otoño civilizatorio. España, Ned Ediciones.

RINCON, O. y URIBE, C. (2015): De Uribe, Santos y otras especies políticas: comunicación de gobierno en Colombia, Argentina y Brasil. Bogotá, Universidad de Los Andes.

ROITMAN, M. (2012): Los indignados. El rescate de la política. Madrid, Akal.

ROVIRA, G. (2017): Activismo en red y multitudes conectadas. Barcelona, Icaria Editorial.

SAMPEDRO, V. (2011): Cibercampaña. Causes y diques para la participación, las elecciones generales de 2008 y su proyección tecnopolítica. Madrid, Editorial Complutense.

SAMPEDRO, V., SÁNCHEZ, J. y POLETTI, M. (2013): Ciudadanía y tecnopolítica electoral: ideales y límites burocráticos a la participación digital. Revista Coherencia, 10 (18), pp. 105-136.

SANZ, L. (2003): Análisis de redes sociales: o cómo representar las estructuras sociales subyacentes. Apuntes de Ciencia y Tecnología, n. 7, pp. 21-29.

SARTORI, G. (1994): Ingeniería constitucional comparada. México, Fondo de Cultura Económica. 
SIERRA, F. (2013): Comunicología y tecnopolítica emergente: nuevas mediaciones y espacios de liberación social. Redes.com, n. 8, pp. 11-19.

SIERRA, F. y GRAVANTE, T. (2018): Networks, movements and technopolitics in Latin America. Switzerland, Palgrave.

SIERRA, F., MANIGLIO, F. y FÁVARO, D. (2018): Políticas de comunicación e integración económica intercontinental. Quito, Ediciones Ciespal.

SITRIN, M. (2012): Horizontalism and the Occupy Movements. Dissent, 59 (2), pp. 74-75.

SOBCHACK, V. (1995): Democratic Franchise and the electronic frontier. Futures, 27 (7), pp. 725-734.

SOENGAS, X. y ASSIF, M. (2017): El ciberactivismo en el proceso de cambio político y social en los países árabes. Comunicar, n. 53, pp. 49-57.

SPIER, S. (2017): Collective Action 2.0. The impact of social media on collective action. United Kingdom, Chandos Publishing.

TARROW, S. (1999): Estado y oportunidades: la estructuración política de los movimientos sociales, en MCADAM, D., MCCARTHY, J. y ZALD, M. (Coords.): Movimientos sociales: perspectivas comparadas. Madrid, Editorial Istmo, pp. 71 99.

(2004): El poder en movimiento: los movimientos sociales, la acción colectiva y la política. Madrid, Alianza Editorial.

TASCON, M. y QUINTANA, Y. (2012): Ciberactivismo. Las nuevas revoluciones de las multitudes conectadas. Madrid, La Catarata.

THOMPSON, J. (1998): Los media y la modernidad. Barcelona, Paidós.

TILLY, C. (2002): Repertorios de acción contestataria en Gran Bretaña: 1758-1834, en TRAUGOTT, M.: Protesta social. Repertorios y ciclos de la acción colectiva. Barcelona, Editorial Hacer, pp.17-47.

Hacer.

(2008): Contienda política y democracia en Europa. Barcelona, Editorial

TILLY, C. y WOODS, L. (2010): Los movimientos sociales 1768-2008. Barcelona, Crítica. 
TORET, J. (2015): Tecnopolítica y 15M: Potencia de las multitudes conectadas. Estudio sobre la gestación y la explosión del 15 M. Barcelona, UOC.

TORMEY, S. (2015): The end of retresentative politics. Cambridge, Polity Press.

TORRES, L. (2015): ¿Quién programa las redes sociales en Internet? El caso de Twitter en el movimiento \#Yosoy132 México. Revista Internacional de Sociología, 73 (2), pp. 1-12.

TURNER, B. (1990): Outline of a theory of citizenship. The Journal of the British Sociological Association, 24 (2), pp. 189-217.

UGARTE, D. (2007): El poder de las redes: manual ilustrado para personas, colectivos y empresas abocados al ciberactivismo. Barcelona, El Cobre Ediciones.

VALENCIA, C. y GARCÍA, C. (2014): Movimientos sociales e internet. Bogotá, Editorial Pontificia Universidad Javeriana.

VELASCO, J.C. (2009): Democracia y deliberación pública. Revista de pensamiento político, n. 6, pp. 70-79.

VERÓN, E. (2005): Interfaces. Sobre la democracia audiovisual avanzada, en FERRY, J. y WOLTON, D.: En el nuevo espacio público. Barcelona, Gedisa, pp. 124-139.

(2015): Teoría de la mediatización: una perspectiva semio-antropológica. ClC Cuadernos de Información y Comunicación, v. 20, pp.173-182.

WASSERMAN, S. y FAUST, K. (2013): Análisis de redes sociales. Métodos y aplicaciones. Madrid, Centro de Investigaciones Sociológicas.

WELP, Y. (2015): Cuando todo lo sólido se desvanece en Twitter. Análisis del movimiento social \#YoSoy132. Postdata, 20 (2), pp. 417-439.

YUEN, S. (2015): Hong Kong After the Umbrella Movement. China Perspectives n. 1, pp. 49-53.

ZANONI, L. (2008): El imperio digital. Argentina, Ediciones B. 
Anexo

El Doctorado en Ciencia Política de la Unidad Académica de Ciencia Política de la Universidad Autónoma de Zacatecas (UAZ), realiza una investigación con fines académicos para conocer qué representa para los cibernautas internet y cómo lo utilizan para participar en temas de interés público. Pedimos tu colaboración para contestar estas preguntas. La encuesta es anónima, no requerimos tu nombre ni tampoco algún dato personal. Agradecemos el apoyo

1. Marca entre qué rango está tu edad

Menos de 11 años $\quad 12-17 \quad 18-24 \quad 25-34 \quad 35-44 \quad 45-54 \quad 55$ y más

2. Señala el género al que perteneces

Masculino Femenino

3. ¿Cuál es tu situación actual?

Trabajo Estudio Trabajo y estudio Ninguna de las anteriores

4. ¿Cuál es tu último nivel de estudios concluido?

Primaria Secundaria Preparatoria Licenciatura Posgrado
Ninguno

5. Indica por favor, cuántas horas pasas en promedio conectado al día en internet Menos de 1 hora 1 hora De 2 a 3 horas De 4 a 5 horas

Más de 5 horas

6. Por favor marca las 3 principales actividades que realizas a través de internet Para enviar y recibir mensajes instantáneos

Para ver videos y escuchar música

Para compartir información en mis redes sociales

Para realizar tareas escolares

Para efectuar compras

Para cuestiones de trabajo

Para opinar sobre temas de interés público

Para informarme de asuntos noticiosos

Otras actividades

7. De los siguientes medios, cuál utilizas más para enterarte de lo que ocurre en el país

$\begin{array}{cllll}\text { Televisión } & \text { Radio } & \text { Periódicos } & \text { Revistas } & \text { Facebook } \\ \text { Twitter } & \text { Páginas web } & \text { Oro Ninguno } & \end{array}$

8. Marca por favor ¿qué red social acostumbras utilizar más?

Facebook Twitter Google+ Instagram Otra

Ninguna 
9. Indica ¿cuáles son los principales tipos de información que acostumbras consultar en internet?

\begin{tabular}{|c|c|c|c|c|}
\hline Educa & Gobierno & Comida & \multicolumn{2}{|c|}{ Derechos } \\
\hline \multicolumn{2}{|c|}{ Deportes } & & & \\
\hline úsica & Economía & Cultura & Moda & \\
\hline Cine & Tecnología & Empleo & Juegos & \\
\hline
\end{tabular}

Otro

10. ¿Qué representa para ti internet?

Una zona de entretenimiento

Una fuente para mantenerme informado

Un lugar público para expresar mis ideas

Un espacio para comunicarme con otros

Un sitio para debatir mis ideas

Un canal para manifestar inconformidades

Otra

11. Ordena de más importante a menos importante, siendo el 5 el más importante y 1 el menos importante, las características que consideres más relevantes para la comunicación en internet:

Comunicarme mediante el anonimato

La rapidez para buscar información

La inmediatez en la comunicación

El acceso a contenidos diversos

La posibilidad de compartir contenidos

12. ¿Consideras que internet es un espacio libre para expresar tus ideas?

Sí No

13. ¿Qué haces cuando un contacto de tu red social (Facebook, Twitter, etc.) publica algún comentario que va en contra de tu manera de pensar?

Ignoro el comentario y sigo navegando

Oculto o elimino el comentario

Debato

Lo denuncio ante la red social

Bloqueo al usuario

Escribo un comentario sin ofender, pero aclaro que no estoy de acuerdo

Otra

14. ¿Qué tan seguido acostumbras consultar información como noticias o programas sobre política en internet?

Diario

Al menos una vez a la semana

Al menos una vez al mes 
Al menos una vez cada seis meses

A menos una vez al año

Nunca

15. ¿Consideras que en internet existe mayor libertad para comentar temas políticos que en la vida real?

Muy de acuerdo Algo de acuerdo $\quad \mathrm{Ni}$ de acuerdo $\mathrm{ni}$

en desacuerdo

Algo en desacuerdo Muy en desacuerdo

16. Asigna una calificación a la confianza que tienes en la información que publican en internet las siguientes instituciones, grupos y medios. Utiliza una escala de 0 para nada de confianza a 10 para absoluta confianza

Gobiernos

Partidos políticos Empresas

Iglesias

Medios de comunicación

Organizaciones civiles

17. Durante el último año, ¿Qué tipos de mensajes de carácter político has compartido a través de tus redes sociales?

Comentarios Enlaces Memes Fotografías Videos Ninguno

18. En tu opinión, ¿Para qué sirve la democracia?

Para acudir a votar libremente

Para elegir a nuevos gobernantes

Para resolver injusticias

Para participar en las decisiones del gobierno

Para que no exista desigualdad

Para vivir en una sociedad libre

Otra

19. ¿Eres seguidor en tus redes sociales (Twitter, Facebook, etc.) del Presidente de la República, algún partido político, dirigente de partido, candidato, gobernador, senador, diputado o alcalde?

Sí No

20. Consideras qué con el uso de internet y las redes sociales, los ciudadanos:

a) Tienen más oportunidades para influir en las decisiones del gobierno

b) Tienen menos oportunidades para influir en las decisiones de gobierno

21. En la actualidad ¿participas en internet en alguna organización, asociación, grupo o movimiento civil?

Sí

No 
22. ¿Qué tan fácil o difícil crees que es organizarse en México con otros ciudadanos a través de internet para trabajar en una causa común?

Muy difícil Difícil Algo difícil Poco fácil Fácil

23. De las siguientes acciones, señala cuáles has realizado a través de redes sociales o internet para resolver un problema que te afecta a ti y a otras personas:

Organizarme con otras personas

Enviar mensajes a medios de comunicación

Quejarme con las autoridades

Pedir apoyo a organizaciones civiles

Firmar cartas virtuales de protesta

Solicitar ayuda a partidos políticos

Colocar mensajes en mis redes

Pedir apoyo a legisladores (diputados/senadores)

Circular mensajes entre mis contactos

No he participado en acciones sociales en internet

Otra acción

24. ¿Qué motivos crees que limitan la participación de las personas en movilizaciones y acciones sociales organizadas por internet?

Temor a represalias

Apatía e indiferencia

Desconocimiento o ignorancia

Carencia de solidaridad

Falta de recursos económicos

Diferencia ideológica

Otros

25. En cuál situación consideras que Internet debe ser regulado

a) Ante una crisis política

b) Debido a causas de seguridad pública

c) Por piratería de libros, discos, películas, etc.

d) Cuando exista un riesgo ambiental

e) Para prevenir sicosis y desorden social

f) Ante violaciones a la vida privada

g) Por la propagación de enfermedades

h) No debe ser regulado 